\title{
Physical Activity and Outdoor Leisure Time Physical Exercise: A Population Study of Correlates and Hindrances in a Resource-Constrained African Setting
}

This article was published in the following Dove Press journal:

Journal of Multidisciplinary Healthcare

\section{Chibuike Ogwuegbu \\ Chigbu (iD) ${ }^{1,2}$ \\ Ursula Berger ${ }^{3}$ \\ Uzochukwu Aniebue ${ }^{2}$ \\ Klaus Georg Parhofer ${ }^{4}$ \\ 'ClH LMU Center for International Health, Medical Center of the University of Munich, Munich, Germany; ${ }^{2}$ Department of Obstetrics and Gynaecology, College of Medicine, University of Nigeria, Nsukka, Nigeria; ${ }^{3}$ Institute for Medical Information Processing, Biometry and Epidemiology, Ludwig-Maximilians University Munich, Munich, Germany; ${ }^{4}$ Department of Medicine 4-Grosshadern, Ludwig- Maximilians University, Munich, Germany}

Correspondence: Chibuike Ogwuegbu Chigbu

Department of Obstetrics and Gynaecology, College of Medicine, University of Nigeria, Nsukka, Nigeria Tel +2348037027l 37

Email chibuike.chigbu@unn.edu.ng
Purpose: The study evaluated the burden of physical inactivity, its correlates, and the selfreported hindrances to outdoor leisure-time physical exercises in Enugu Nigeria. It also evaluated the prevalence of leisure-time outdoor physical exercise and its correlates in Enugu Nigeria.

Patient and Methods: This is a cross-sectional household survey involving 6628 individuals aged 20 to 60 years from 2848 households in Enugu Nigeria. Binary logistic regression and multinomial regression analyses were carried out as appropriate. Estimates were weighted to account for the actual population distribution of important sociodemographic variables and reported with the $95 \%$ confidence interval.

Results: The burden of physical inactivity was 32.68\% (95\% CI: $31.24-34.12 \%$ ). Urban dwellers were less likely to be physically active than rural dwellers $(\mathrm{AOR}=0.477 ; 95 \% \mathrm{CI}=$ $0.410-0.555$ ). For each year increase in age, the odds of being physically active decreases by a factor of $0.993(\mathrm{AOR}=0.993 ; 95 \% \mathrm{CI}=0.988-0.998)$. Gender, income level and education did not predict physical inactivity. Physical inactivity significantly increases the odds of being obese by a factor of 1.428 (AOR: 1.428 ; 95\% CI: 1.190-1.714). Only 6.45\% (95\% CI: 5.82\%-7.09\%) participants reported at least once a week outdoor leisure-time physical exercise. The major barriers include lack of time and lack of interest in outdoor leisure-time physical exercise.

Conclusion: The burden of physical inactivity is high, while the level of outdoor physical exercise is low in Enugu, Nigeria. Urban dwelling and increasing age are risk factors for physical inactivity. Living in urban areas, being less than 40 years of age, having a university education, and a high personal income are factors that positively drive outdoor leisure-time physical exercises. Policies that will promote awareness of the health benefits of physical activity and outdoor physical exercise are needed if Nigeria is to achieve the global mandate of reducing physical inactivity by $10 \%$ in the year 2025 .

Keywords: physical inactivity, exercise, determinants, obesity, Nigeria

\section{Introduction}

As the world battles the pandemic of obesity and its associated adverse health outcomes, there is a growing focus on physical activity as an essential preventive and management element. ${ }^{1}$ Although the aetiology of obesity is complex and multi-faceted, a simplified view of obesity is that of the result of an imbalance between energy intake and expenditure. ${ }^{2,3}$ Physical activity is a very vital factor in the energy intake and expenditure 
equation. Also, physical activity plays a role as a modulator of the phenotypic expression of obesity polygenes. ${ }^{4}$ Epidemiological evidence linking physical inactivity to obesity has shown consistent results across all income classes, including low-, middle- and high-income countries of the world. ${ }^{5,6}$ The trend in the global obesity epidemic parallels that of physical inactivity and nutritional transition, further supporting the synergistic role of the three factors in the development of the worldwide epidemic of obesity. ${ }^{7,8}$

Lack of physical activity is the $4^{\text {th }}$ leading risk factor for global mortality accounting for $6 \%$ of global deaths. ${ }^{9}$ Physical inactivity is a significant risk factor for several non-communicable diseases like cancer of the breast, cancer of the colon, diabetes, and ischaemic heart diseases. It is estimated that lack of physical activity is implicated as a cause of a quarter of breast and colon cancers and nearly a third of Ischaemic heart diseases. ${ }^{9}$ Physical inactivity also acts synergistically with obesity to cause some critical metabolic diseases. ${ }^{10}$

The burden of non-communicable diseases is rising in Africa and other low-income continents. Africa has been known to carry the double burden of infectious diseases and diseases of undernutrition. ${ }^{11}$ The rising prevalence of non-communicable diseases is a significant cause for concern as that would mean a triple burden of diseases for a continent with fragile health systems. As a modifiable risk factor for non-communicable diseases, ${ }^{12}$ physical inactivity ought to receive similar attention in Africa as in high-income countries. Unfortunately, this is not so as the massive volume of research work on physical activity in high-income countries contrasts with the sparse information from African countries. ${ }^{7}$

In Nigeria, there is a paucity of research on physical activity. A Medline search yielded very few studies from Nigeria on physical activity. ${ }^{13-16}$ None of the studies was population-based, hence making generalization of the findings to the population difficult. The previous studies evaluated small subsets of the population like people living with type 2 diabetes, ${ }^{13,15}$ university students ${ }^{14}$ and government employees. ${ }^{16}$ Furthermore, none of the studies evaluated the hindrances to outdoor leisure-time physical exercises.

This study aimed to evaluate the burden of physical inactivity, and its correlates. It also evaluated the prevalence of leisure-time outdoor physical exercise and its correlates as well as the self-reported hindrances to outdoor leisuretime physical exercises in a large state-wide representative sample of Enugu State Nigeria. Understanding the epidemiology of physical inactivity in such low-income populations will "help guide the development of policies and programmes that will increase activity levels and reduce the burden of non-communicable diseases". ${ }^{17}$

\section{Materials and Methods Study Setting}

The study population comprised adults aged 20 to 60 years. Enugu state is one of the 36 states of Nigeria and has a population of approximately 3.3 million people comprising 1.6 million males and 1.7 million females. The population of individuals aged 20-60 years of age is 1.6 million per the 2006 national population census. ${ }^{18}$ For purposes of population census, the National Population Commission demarcated each state in Nigeria into areas with definite geographical boundaries called enumeration areas (EA). The average number of households per EA is 48 , while the average number of individuals in a household is about four.

\section{Study Design}

This cross-sectional study took place in Enugu, Nigeria. The study is part of a large population study on obesity in Enugu Nigeria. Part of this large study has already been published. ${ }^{19,20}$

\section{Sampling and Sample Distribution}

Cluster randomized sampling was done. The EAs served as clusters for the study. Sixty-seven clusters comprising 47 urban clusters and 20 rural clusters were sampled. To achieve a representative sample, the urban area was subcategorized into the lower-class, middle-class, and upper-class according to the economic class of the predominant population residing in the area. Allocation of the number of clusters to the urban sub-classes was proportionate to the population size of the sub-classes. Six clusters were sampled in the upper-class areas, 15 clusters in the middle-class areas and 20 clusters in the lower-class areas. The Final selection of clusters (EAs) for sampling within the sub-classes and the rural areas was by simple random sampling. Each EA in each state in Nigeria is identified with a unique number code by the National Population Commission of Nigeria. The number codes of all the EAs in each sub-class and the rural areas were entered into a computer program. The EAs were randomly selected until the total allocated cluster for each sub-class and rural area were selected. 


\section{Sample Size Determination}

A minimum sample size of 6459 adults was estimated using the sample size formula for cluster representative sample. The assumptions used in calculating the sample size were the national obesity prevalence of $8 \%$, a $95 \%$ confidence interval width of \pm 1 percentage point, an estimated design effect of 2.24, and an estimated response rate of $98 \%$. These parameters were obtained from the Nigeria Demographic and Health Survey. ${ }^{18}$

The sampling unit is the individual. Every consenting household within the selected EA was sampled, and all consenting individuals within the age range of 20 to 60 years were interviewed, and anthropometric measurements were taken. The anthropometric measurements included height, weight, waist circumference and triceps skin fold thickness. The measurements were taken by appropriately trained personnel using the National Health and Nutrition Examination Survey (NHANES) anthropometry procedure manual. ${ }^{21}$

\section{Data Collection Tool}

The data were collected using a structured, intervieweradministered questionnaire. The questions in the questionnaire were adapted from the global school health survey (GSHS). ${ }^{22}$ The modified questionnaire was tested in a pilot study involving two randomly selected urban streets and one rural community. The sample frame for the pilot study was the official list of streets in the city center and communities in rural areas. Thirty households were listed for the pilot study, 18 households from the city center and 12 households from the rural areas. Trained household data collectors collected the field data.

\section{Data Analysis}

The proportions of the population that are physically active and inactive were estimated using weighted estimates, taking the population distributions in the different strata into account. Z-tests were employed to compare the weighted prevalence of physical inactivity between relevant population sub-groups namely: males and females, urban and rural residents, younger and older adults $(\leq 40$ years of age and $>40$ years of age). Z-test was also used to compare the weighted proportion of physically active persons who were obese and that of physically inactive persons who were obese. Binary logistic regression was used to evaluate the determinants of physical activity with the response variable as physically active or inactive. The predicting variables were the age in years, gender, urban/ rural residence, income class and education. Multinomial regression was used to evaluate the effect of physical activity on obesity and overweight. The dependent variable was BMI category of underweight, normal, overweight, and obese with normal weight as the response category. The independent variable was being physically active or not, while age and gender were confounding variables. In both the binary and multinomial logistic regressions, adjusted odds ratios (AOR) together with $95 \%$ confidence intervals and p-values of the Wald test were reported.

The proportions of the population that reported at least once a week outdoor leisure-time physical exercise were weighted, taking the population distributions in the different strata into account. The weighted proportions were compared between relevant population subgroups, namely: males and females, urban and rural residents, younger and older adults ( $\leq 40$ years of age and $>40$ years of age) using z-tests. Binary logistic regression was also used to evaluate the predictors of outdoor leisure-time physical exercise with the response variable as no outdoor leisure-time physical exercise or at least once a week outdoor leisure-time physical exercise. The predicting variables were age, gender, urban/rural residence, income class and education. Adjusted odds ratios (AOR) together with $95 \%$ confidence intervals and $\mathrm{p}$-values of the Wald test were reported.

The reported hindrances to outdoor leisure-time physical exercise were compared between urban and rural residents using Chi-square tests.

A P-value of less than 0.05 was considered significant. The World Health Organisation (WHO) definition of Physical inactivity as fewer than 150 minutes/week spent in moderate or vigorous physical activities was adopted. Income was classified based on monthly income, into low $(<36,000$ Nigerian Naira), middle (36,000-180,000 Nigerian Naira) and high ( $>180,000$ Nigerian Naira), using an adaptation of the income class classification of the African Development Bank. ${ }^{23}$ Obesity was defined using the WHO body mass index cut off of $30 \mathrm{~kg} / \mathrm{m}^{2.24}$ Data analysis was done using the IBM SPSS software version 20.

\section{Ethical Considerations}

The study protocol was reviewed and approved by the ethical committees of both the University of Nigeria Teaching Hospital, Enugu and the Ludwig Maximillian University, Munich, Germany.

Written informed consent was obtained before participation. 
The study was conducted in accordance with the Declaration of Helsinki.

\section{Results}

A total of 6628 individuals comprising $41.5 \%(n=2752)$ males and $58.5 \%(n=3876)$ females participated in the study. The mean age of the participants was 34.9 years $( \pm 13.2$ years $\mathrm{SD})$. Table 1 shows the sociodemographic characteristics of the participants.

\section{Burden of Physical Inactivity}

The overall weighted prevalence of physical activity was 67.32\% (95\% CI: 65.88\%-68.76\%), while the figures for physical inactivity were $32.68 \%$ (95\% CI: 31.24-34.12\%). The weighted proportion of physically inactive males was $31.96 \%$ (95\% CI: 29.69\%-34.23\%). The weighted proportion of physically inactive females was 33.13\% (95\% CI: 31.27-34.99\%). The difference was not statistically significant $(\mathrm{p}=0.437)$. According to residence, $44.73 \%(95 \%$ CI: $43.27 \%-46.19 \%$ ), urban residents were physically inactive. The corresponding figure for rural residents was

Table I Socioeconomic Characteristics of Respondents

\begin{tabular}{|l|l|l|}
\hline Characteristic & Number & Percentage (\%) \\
\hline $\begin{array}{l}\text { Gender } \\
\text { Female }\end{array}$ & 3876 & \\
Male & 2752 & 48.5 \\
\hline Residence & & \\
Urban & 4630 & 69.9 \\
Rural & 1998 & 30.1 \\
\hline Age distribution (years) & & \\
S40 & 4380 & 66.1 \\
>40 & 2248 & 33.9 \\
\hline Marital status & & \\
Single & 3374 & 50.9 \\
Married & 3041 & 45.9 \\
Divorced & 22 & 0.3 \\
Separated & 23 & 0.3 \\
Widowed & 168 & 2.5 \\
\hline Education & & \\
No university education & 5482 & 82.7 \\
University education & 1146 & 17.3 \\
\hline Income class & & \\
Upper & 644 & 9.7 \\
Middle & 1745 & 26.3 \\
Lower & 2187 & 0.8 \\
University community & 53 & \\
\hline
\end{tabular}

27.51\% (95\% CI: 25.56\%-29.47\%). The difference was statistically significant $(\mathrm{p}<0.001)$. The weighted prevalence of inactivity for participants aged 40 years and below was $31.41 \%$ (95\% CI: $29.50 \%-33.32 \%$ ), the corresponding figure for those aged above 40 years was $34.61 \%$ (95\% CI: $32.37 \%-36.84 \%$ ). The difference was statistically significant $(\mathrm{P}=0.033)$.

\section{Predictors of Being Physically Active}

Binary logistic regression showed that age and place of residence (urban versus rural) had a significant association with physical activity. Urban dwellers were less likely to be physically active compared to rural dwellers (AOR = 0.477 ; 95\% CI $=0.410-0.555)$. For each year increase in age, the odds of being physically active decreases by a factor of 0.993 (AOR $=0.993 ; 95 \% \mathrm{CI}=0.988-0.998)$. Gender, income level and education did not predict the likelihood of being physically active or not (Table 2).

\section{Physical Inactivity and Obesity/ Overweight}

The weighted proportion of inactive persons who were obese was $7.89 \%$ (95\% CI: $6.39 \%-9.39 \%$ ), while the proportion of active persons who were obese was $6.16 \%$ (95\% C: $5.30 \%$ $7.02 \%$ ). The difference was statistically significant, $\mathrm{p}<0.006$. The weighted proportion of inactive persons who were overweight (20.69\%; 95\% CI: 18.35\%-23.04\%) was significantly higher than that of active persons who were overweight (18.35\%; 95\% CI: 16.93\%-19.77\%), $\mathrm{p}=0.018$.

Physical inactivity had a significant impact on obesity and overweight after controlling for gender and age. Physical inactivity significantly increases the odds of

Table 2 Predictors of Physical Activity (Binary Logistic Regression)

\begin{tabular}{|l|l|l|l|l|}
\hline \multirow{2}{*}{ Predictor } & AOR & \multicolumn{2}{l|}{$\begin{array}{l}\text { 95\% Confidence } \\
\text { Interval }\end{array}$} & \multirow{2}{*}{ p-value } \\
\cline { 3 - 4 } & & Lower & Upper & \\
\hline Age & $0.993^{*}$ & 0.988 & 0.998 & 0.008 \\
Male gender & 0.979 & 0.864 & 1.109 & 0.735 \\
Urban residence & $0.477^{*}$ & 0.410 & 0.555 & $<0.001$ \\
Income-class a & & & & 0.061 \\
Low-income class & 1.164 & 0.930 & 1.458 & 0.184 \\
Middle-income class & 0.914 & 0.729 & 1.146 & 0.436 \\
Years of education & 1.020 & 1.000 & 1.040 & 0.050 \\
Constant & 2.547 & & \multicolumn{2}{|l}{0.000} \\
\hline
\end{tabular}

Notes: ${ }^{a}$ reference category: upper-income class. *Significant, ie, $p<0.05$. Abbreviation: AOR, adjusted odds ratio. 
Table 3 Effect of Physical Inactivity on Obesity and Overweight (Multinomial Regression)

\begin{tabular}{|c|c|c|c|c|c|}
\hline \multirow[t]{2}{*}{ BMI Category ${ }^{a}$} & \multirow[t]{2}{*}{ Variable } & \multirow[t]{2}{*}{ AOR } & \multicolumn{2}{|c|}{ 95\% Confidence Interval } & \multirow[t]{2}{*}{ p-value } \\
\hline & & & Lower & Upper & \\
\hline Obese & $\begin{array}{l}\text { Intercept } \\
\text { Physically inactive } \\
\text { Physically active }{ }^{b} \\
\text { Male gender } \\
\text { Female gender }{ }^{b} \\
\text { Urban residence } \\
\text { Rural residence }{ }^{b} \\
\leq 40 \text { years of age } \\
>40 \text { years of age }{ }^{b}\end{array}$ & $\begin{array}{l}I .428^{*} \\
0.318^{*} \\
2.421^{*} \\
0.343^{*}\end{array}$ & $\begin{array}{l}1.190 \\
0.257 \\
1.927 \\
0.285\end{array}$ & $\begin{array}{l}1.714 \\
0.393 \\
3.043 \\
0.413\end{array}$ & $\begin{array}{l}<0.001 \\
<0.001 \\
<0.001 \\
<0.001 \\
<0.001\end{array}$ \\
\hline Overweight & $\begin{array}{l}\text { Intercept } \\
\text { Physically inactive } \\
\text { Physically active }^{b} \\
\text { Male gender } \\
\text { Female gender } \\
\text { Urban residence }^{b} \\
\text { Rural residence } \\
\leq 40 \text { years of age } \\
>40 \text { years of age }\end{array}$ & $\begin{array}{l}1.23 I^{*} \\
0.762^{*} \\
.724^{*} \\
0.725^{*}\end{array}$ & $\begin{array}{l}1.089 \\
0.674 \\
1.494 \\
0.638\end{array}$ & $\begin{array}{l}1.391 \\
0.860 \\
1.988 \\
0.825\end{array}$ & $\begin{array}{l}<0.001 \\
0.001 \\
<0.001 \\
<0.001 \\
<0.001\end{array}$ \\
\hline Underweight & $\begin{array}{l}\text { Intercept } \\
\text { Physically inactive } \\
\text { Physically active }{ }^{b} \\
\text { Male gender } \\
\text { Female gender }{ }^{b} \\
\text { Urban residence } \\
\text { Rural residence }{ }^{b} \\
\leq 40 \text { years of age } \\
>40 \text { years of age }{ }^{b}\end{array}$ & $\begin{array}{l}1.022 \\
1.186 \\
0.517^{*} \\
0.900\end{array}$ & $\begin{array}{l}0.829 \\
0.973 \\
0.420 \\
0.728\end{array}$ & $\begin{array}{l}1.261 \\
1.447 \\
0.635 \\
1.112\end{array}$ & $\begin{array}{l}<0.001 \\
0.837 \\
0.092 \\
<0.001 \\
0.327\end{array}$ \\
\hline
\end{tabular}

Notes: ${ }^{a}$ Reference category for BMI class is normal weight. ${ }^{\mathrm{b}}$ Reference category for predictor variable; $*$ Significant (ie, $\mathrm{p}<0.05$ ).

being obese by a factor of 1.428 (AOR: $1.428 ; 95 \%$ CI: $1.190-1.714)$. Similarly, physical inactivity significantly increases the odds of being overweight by a factor of 1.231 (AOR: 1.231; 95\% CI: 1.089-1.391). These are shown in Table 3.

\section{Outdoor Leisure-Time Physical Exercise}

Only 6.45\% (95\% CI: 5.82\%-7.09\%) participants reported at least once a week outdoor leisure time physical exercises while $93.55 \%$ (95\% CI: 92.91\%-94.18\%) did not. The weighted proportions of males and females who reported at least once a week outdoor leisure time physical exercises were $7.42 \%$ (95\% CI: $6.37 \%-8.46 \%$ ) and 5.73\% (95\% CI: 4.94\%-6.53\%) respectively. The difference was statistically significant $(\mathrm{P}=0.012)$. Only $3.46 \%(95 \% \mathrm{CI}$ : $2.66 \%-4.26 \%)$ rural dwellers reported at least once a week outdoor leisure-time physical exercise. The corresponding figure for urban dwellers was $13.44 \%$ (95\% CI: $12.46 \%$ $14.43 \%)$. The difference was statistically significant $(\mathrm{P}<$ 0.001 ). Only $7.04 \%$ ( $95 \%$ CI: $6.13 \%-7.95 \%$ ) persons below the age of 40 years and $5.53 \%$ (95\% CI: $4.62 \%$ $6.44 \%$ ) persons above the age of 40 years engage in outdoor leisure-time physical exercise at least once a week. The difference was statistically significant $(\mathrm{P}=0.0 .02)$.

\section{Predictors of Outdoor Leisure-Time Physical Exercise}

Binary logistic regression analysis showed that individuals aged 40 years and below are about 1.4 times more likely to engage in outdoor leisure-time physical exercise than those aged above 40 years (AOR=1.367; 95\% CI=1.095-1.707). Males were more likely to engage in outdoor leisure-time physical exercise than females. However, this did not reach statistical significance $(\mathrm{AOR}=1.225 ; 95 \% \mathrm{CI}=0.991-1.514)$. 
Table 4 Predictors of Outdoor Leisure-Time Physical Exercise (Binary Logistic Regression)

\begin{tabular}{|l|l|l|l|l|}
\hline \multirow{2}{*}{ Predictor } & AOR & \multicolumn{2}{l|}{$\begin{array}{l}\text { 95\% Confidence } \\
\text { Interval }\end{array}$} & \multirow{2}{*}{ p-value } \\
\cline { 3 - 4 } & & Lower & Upper & \\
\hline$\leq 40$ years of age & $1.367^{*}$ & 1.095 & 1.707 & 0.006 \\
Male gender & 1.225 & 0.991 & 1.514 & 0.061 \\
Urban residence & $2.989 *$ & 2.114 & 4.227 & $<0.001$ \\
Income-class a & & & & \\
Low-income class & $0.536 *$ & 0.367 & 0.782 & 0.001 \\
Middle-income class & $0.535^{*}$ & 0.394 & 0.727 & $<0.001$ \\
University education & $3.107^{*}$ & 2.237 & 4.315 & $<0.001$ \\
\hline
\end{tabular}

Notes: ${ }^{a}$ Reference category for income class $=$ high-income class. $*$ Significant $(p<0.05)$.

Urban dwellers are nearly three times more likely to engage in outdoor leisure-time physical exercise compared to rural dwellers $(\mathrm{AOR}=2.989 ; 95 \% \mathrm{CI}=2.114-4.227)$. Compared to the high-income class, the low-income class are less likely to engage in outdoor leisure-time physical exercise (AOR= $0.536 ; 95 \% \mathrm{CI}=0.371-0.782$ ). Similarly, those in the middleincome class are less likely to do outdoor leisure-time physical exercise compared to the high-income class $(\mathrm{AOR}=0.535$; $95 \% \mathrm{CI}=0.394-0.727)$. Having university education increases the likelihood of outdoor leisure-time physical exercise by three times $(\mathrm{AOR}=3.107 ; 95 \% \mathrm{CI}=2.237-4.315)$. Table 4 summarises the outcome of the binary logistic regression analysis on the predictors of outdoor leisure-time physical exercise.

\section{Hindrances to Outdoor Leisure-Time Physical Exercise}

Amongst urban dwellers, 1183 (25.6\%) respondents did not give any reason, $846(18.3 \%)$ reported lack of time while $468(10.1 \%)$ reported fear of criminals as their most important reason for not engaging in outdoor leisure time physical exercises. The corresponding figures among the rural residents were $705(35.5 \%), 582(29.1 \%)$ and 23 (1.2\%) (Table 5).

\section{Discussion}

The result revealed a prevalence of physical inactivity of $32.68 \%$, which is relatively high. The prevalence of physical inactivity reported by previous studies of specific restricted populations from Nigeria ranged from $31 \%$ to $41 \%{ }^{14,15}$ The reported prevalence of physical inactivity from other African countries ranged from $17.4 \%$ in Kenya $^{25}$ through $33 \%$ among black South African
Table 5 Hindrances to Outdoor Leisure Time Outdoor Physical Exercises in Urban and Rural Areas

\begin{tabular}{|c|c|c|c|}
\hline Hindrance & $\begin{array}{l}\text { Urban } \\
\text { Residents, } \\
\mathrm{N}=4630\end{array}$ & $\begin{array}{l}\text { Rural } \\
\text { Residents, } \\
\mathrm{N}=1998\end{array}$ & P-value \\
\hline No reason & II 83 (25.6\%) & 705 (35.3\%) & $<0.001$ \\
\hline Not hindered & 969 (20.9\%) & 127 (6.4\%) & $<0.001$ \\
\hline Lack of time & 846 (I8.3\%) & 582 (29.1\%) & $<0.001$ \\
\hline $\begin{array}{l}\text { Fear of } \\
\text { criminals }\end{array}$ & 468 (10.1\%) & $23(1.2 \%)$ & $<0.001$ \\
\hline Fear of traffic & 391 (8.4\%) & $8(0.4 \%)$ & $<0.001$ \\
\hline $\begin{array}{l}\text { In-door } \\
\text { exercise }\end{array}$ & 373 (8.1\%) & $62(3.1 \%)$ & $<0.001$ \\
\hline Lack of interest & 345 (7.5\%) & $462(23.1 \%)$ & $<0.001$ \\
\hline Disability & 45 (I.0\%) & $24(1.2 \%)$ & 0.429 \\
\hline III-Health & $10(0.2 \%)$ & $5(0.3 \%)$ & 1.000 \\
\hline
\end{tabular}

women $^{26}$ to $37.6 \%$ in Uganda. ${ }^{27}$ In a study involving 28 countries in Europe, the prevalence of physical inactivity was reported as $28 \%{ }^{28}$ A report from a global survey involving 122 nations put the global prevalence of physical inactivity at $31.1 \%{ }^{17}$ The level of physical inactivity in this study is close to the worldwide estimate. However, this level of physical inactivity in Nigeria is likely to increase rapidly and surpass the global estimate as the economy of Nigeria improves, and more individuals acquire cars for routine transportation on improved road networks. An improved economy will also reduce the level of physical activity from manual labour as the use of machines will increase. The World Health Organisation member states are working to reduce the prevalence of physical inactivity by $10 \%$ in the year $2025 .{ }^{1}$ Currently, Nigeria does not have any national policy on physical activity. The findings of this study bring to the fore the substantial current burden of physical inactivity in Nigeria, and the potential escalated burden that the country must contend with in the future as her economy improves. It is time to begin to give physical activity the attention that it deserves in Nigeria.

Although gender did not have a significant independent impact on physical activity in this study, previous studies from various regions of the globe have reported higher proportions of physical inactivity in females than males. $^{7,14,27-29}$ Rural dwellers were more than twice as likely to be physically active as urban dwellers. This finding supports the finding of other previous research works in Nigeria and Europe. ${ }^{15,28}$ Reports from the United States show mixed results. Most studies reported 
more physical inactivity in rural dwellers than urban dwellers. $^{30,31}$ However, a recent report from the United States National Health and Nutrition Examination Survey (NHANES) showed that although rural dwellers are less active in high-intensity physical activity, total physical activity is more amongst rural dwellers than urban dwellers. $^{32}$

Urban/rural effects on physical activity are mediated through socioeconomic status and built physical environment. $^{33}$ Physical activity tends to be higher in neighbourhoods with higher walkability. ${ }^{34,35}$ In Nigeria, rural residents are usually poor and only very few could afford personal cars. Furthermore, rural roads are typically inadequate and hardly motorable, making vehicular transportation more challenging in rural areas. This compels the rural dwellers to walk more than urban residents where the roads are better and the residents richer. This is a significant finding as government policies on physical activity must factor in these variables. Another correlate of physical activity from this study is age. As age increases, the odds of meeting the approved level of physical activity reduces. This is similar to findings by previous researchers on the subject matter from Nigeria, Europe and South America. ${ }^{14,29,36,37}$ The proportions of physically inactive persons who are obese and overweight are significantly higher than the proportion of physically active persons who are obese and overweight. Physical inactivity also increases the odds of being obese and overweight by a factor of 1.4 and 1.2, respectively, and these impacts are significant. Physical inactivity is a known risk factor for obesity.

Income level did not predict physical activity in this study. This contrasts with findings from a study in northern Nigeria, where higher income decreased the odds of physical activity. ${ }^{38}$ The vast socio-cultural difference between northern and southern Nigeria could be an explanatory factor. Also, the study from northern Nigeria was from a cross-section of urban residents only and was therefore not representative of the general population. Education and income and income are reported to increase the odds of physical activity in high-income countries. ${ }^{39}$ Social desirability of large body sizes in Nigeria, where a high level of veneration of large body size has been reported, could be an explanatory factor. ${ }^{19}$

Outdoor leisure-time physical exercise is another essential component of physical activity. Only 6.45\% of the population in this study reported at least once a week outdoor leisure-time physical exercise. This is quite low and demands actions that will encourage more people to be involved in leisure-time outdoor physical exercise. Urban dwellers are about three times more likely to engage in outdoor leisure-time physical exercise than rural dwellers, and individuals with university education are three times more likely to engage in outdoor leisuretime physical exercise than those without a university education. This is quite understandable as education increases the awareness and appreciation of the importance of leisure-time physical exercise. More people with university education reside in urban areas. The urban areas in Enugu have few recreational parks for leisure-time physical exercise while the rural areas have none.

Furthermore, urban residents do less manual work, and less physical activity as shown in this study; hence may find outdoor leisure-time physical exercise more desirable than rural residents who do more manual labour and more physical activity. These are the likely factors that could explain the urban-rural difference in outdoor leisure-time physical exercise. Being in the high-income class and age 40 years and below are significantly associated with increased outdoor leisure-time physical exercise. These are similar to the situation in Europe. ${ }^{40}$

The hindrances to outdoor leisure-time physical exercise are noteworthy. A large proportion (46.5\% of urban residents and $41.7 \%$ of rural residents) of respondents had no reason or were not hindered from outdoor leisure-time physical exercise by any factor or were hindered by lack of interest in outdoor leisure-time physical exercise. This is an important observation. Appropriate promotional policies on outdoor leisure-time physical exercise have the potential of driving a positive behaviour change on this subset of the population. It is interesting to note that the fear of criminals $(10.1 \%$ for urban and $1.2 \%$ for rural residents) and fear of traffic (8.4\% for urban and $0.4 \%$ for rural residents) were not significant hindrances to outdoor leisure-time physical exercise. Fear of crime and traffic were listed by WHO as barriers to physical exercise. ${ }^{1}$ In Europe and North America, day length and weather conditions are reported as essential barriers to outdoor physical exercise. ${ }^{40,41}$ A significantly higher proportion of rural dwellers reported lack of time and lack of interest as hindrances to outdoor leisure-time physical exercise than urban dwellers. In contrast, more urban dwellers report fear of criminals, fear of traffic and indoor exercises than rural dwellers. These findings may be found useful in physical activity policy formulation. 
The strength of this study lies in its adequate power and the population-representative nature of the study sample, thus making a generalization of the findings of the study reasonable. However, the study is not without limitations. It is a cross-sectional study; hence, biases inherent to such studies like recall bias do apply in the study. Furthermore, self-reported physical activity was evaluated in this study and this could also introduce a recall bias.

In conclusion, the burden of physical inactivity (32.68\%) in south-eastern Nigeria is high. Living in urban areas, and increasing age are factors associated with an increase in physical inactivity. The level of outdoor leisure physical exercise is very low, with only $6.45 \%$ of adults reporting at least once weekly outdoor leisure-time physical exercise. The major barriers include lack of time and lack of interest in outdoor leisure-time physical exercise. Living in urban areas, being less than 40 years of age, having a university education, and a high personal income are factors that positively drive outdoor leisure-time physical exercises. The findings of the study suggest that physical activity policies that will promote awareness of the health benefits of physical activity and outdoor physical exercise are needed if Nigeria is to achieve the global mandate of reducing physical inactivity by $10 \%$ in the year 2025 . The representative nature of the data provided makes it a veritable tool for physical activity policy development in Nigeria.

\section{Funding}

There is no funding to report.

\section{Disclosure}

This article is derived from a $\mathrm{PhD}$ Thesis project of the lead author (CCO) of the Center for International Studies, Ludwig-Maximilians University, Munich Germany. ${ }^{42}$ The authors report no other potential conflicts of interest for this work.

\section{References}

1. WHO. Global NCD Target: Reducephysical Inactivity. World Health Organization. Available from: https://www.who.int/beat-ncds/takeaction/policy-brief-reduce-physical-inactivity.pdf. Accessed September 10, 2020.

2. Yang W, Kelly T, He J. Genetic epidemiology of obesity. Epidemiol Rev. 2007;29:49-61. doi:10.1093/epirev/mxm004

3. Nguyen DM, El-Serag HB. The epidemiology of obesity. Gastroenterol Clin North Am. 2010;39(1):1-7. doi:10.1016/j. gtc.2009.12.014

4. Ross SE, Flynn JI, Pate RR. What is really causing the obesity epidemic? A review of reviews in children and adults. $J$ Sports Sci. 2016;34(12):1148-1153. doi:10.1080/02640414.2015.1093650
5. Milton K, Macniven R, Bauman A. Review of the epidemiological evidence for physical activity and health from low- and middle-income countries. Glob Public Health. 2014;9(4):369-381. doi:10.1080/17441692.2014.894548

6. Fogelholm M. Physical activity, fitness and fatness: relations to mortality, morbidity and disease risk factors. A systematic review. Obes Rev. 2010;11(3):202-221. doi:10.1111/j.1467-789X.2009.00653.x

7. Bauman AE, Reis RS, Sallis JF, Wells JC, Loos RJ, Martin BW. Correlates of physical activity: why are some people physically active and others not? Lancet (London, England). 2012;380 (9838):258-271. doi:10.1016/S0140-6736(12)60735-1

8. Serra-Majem L, Bautista-Castaño I. Etiology of obesity: two "key issues" and other emerging factors. Nutricion hospitalaria. 2013;28 (Suppl 5):32-43.

9. Bao PP, Cai H, Peng P, et al. Body mass index and weight change in relation to triple-negative breast cancer survival. Cancer Causes Control. 2016;27(2):229-236. doi:10.1007/s10552-015-0700-7

10. Qin L, Knol MJ, Corpeleijn E, Stolk RP. Does physical activity modify the risk of obesity for type 2 diabetes: a review of epidemiological data. Eur J Epidemiol. 2010;25(1):5-12. doi:10.1007/s10654009-9395-y

11. Global status report on non-communicable diseases 2010. WHO; 2010. Available from: https://www.who.int $/ \mathrm{nmh} /$ publications $/ \mathrm{ncd}$ report_full_en.pdf. Accessed November 6, 2020.

12. Hamdy O, Uwaifo GI, Oral EA Obesity. 2020. Available from: https://emedicine.medscape.com/article/123702-overview. Accessed November 6, 2020.

13. Adeniyi AF, Ogwumike OO. Physical activity and energy expenditure: findings from the Ibadan Pregnant Women's Survey. Afr J Reprod Health. 2014;18(2):117-126.

14. Adegoke BOA, Oyeyemi AL. Physical inactivity in Nigerian young adults: prevalence and socio-demographic correlates. $J$ Phys Act Health. 2011;8(8):1135-1142. doi:10.1123/jpah.8.8.1135

15. Oyewole OO, Odusan O, Oritogun KS, Idowu AO. Physical activity among type-2 diabetic adult Nigerians. Ann Afr Med. 2014;13 (4):189-194. doi:10.4103/1596-3519.142290

16. Oladimeji AM, Fawole O, Nguku P, Nsubuga P. Prevalence and factors associated with hypertension and obesity among civil servants in Kaduna, Kaduna State, June 2012. Pan Afr Med J. 2014;18 Suppl 1(Supp11):13.

17. Hallal PC, Andersen LB, Bull FC, Guthold R, Haskell W, Ekelund U. Global physical activity levels: surveillance progress, pitfalls, and prospects. Lancet (London, England). 2012;380(9838):247-257. doi:10.1016/S0140-6736(12)60646-1

18. National Bureau of Statistics Nigeria. Demographics Statistics Bulletin. Abuja Nigeria: National Bureau of Statitics Nigeria; 2018; 2017.

19. Chigbu CO, Aniebue UU, Berger U, Parhofer KG. Impact of perceptions of body size on obesity and weight management behaviour: a large representative population study in an African setting. J Public Health (Oxf). 2019. doi:10.1093/pubmed/fdz127

20. Chigbu CO, Parhofer KG, Aniebue UU, Berger U. Prevalence and sociodemographic determinants of adult obesity: a large representative household survey in a resource-constrained African setting with double burden of undernutrition and overnutrition. $J$ Epidemiol Community Health. 2018;72(8):702-707. doi:10.1136/jech-2018-210573

21. Center for Disease Control. National Health and Nutrition Examination Survey Anthropometry Procedures Manual. CDC; 2007.

22. World Health Organization. Global school health survey questionnaire core expanded. 2009. Available from: https://www.who.int/ ncds/surveillance/gshs/GSHS_Questionnaire_Core_Expanded_2009_ English.pdf. Accessed November 6, 2020.

23. African Development Bank. The Middle of the Pyramid: dynamics of the Middle Class in Africa. 2011. Available from: https://www.afdb. org/sites/default/files/documents/publications/the_middle_of_the_pyr amid_the_middle_of_the_pyramid.pdf. Accessed September 10, 2020. 
24. World Health Organization. Obesity and overweight 2016. Available from: https:/www.who.int/en/news-room/fact-sheets/detail/obesityand-overweight. Accessed November 6, 2020.

25. Nigatu Haregu T, Khayeka-Wandabwa C, Ngomi N, Oti S, Egondi T, Kyobutungi C. Analysis of patterns of physical activity and sedentary behavior in an urban slum setting in Nairobi, Kenya. J Phys Act Health. 2016;13(8):830-837. doi:10.1123/jpah.2015-0510

26. Gradidge PJ, Crowther NJ, Chirwa ED, Norris SA, Micklesfield LK. Patterns, levels and correlates of self-reported physical activity in urban black Soweto women. BMC Public Health. 2014;14:934. doi:10.1186/1471-2458-14-934

27. Kirunda BE, Wamani H, Fadnes LT, Van den Broeck J, Tylleskär T. Objectively assessed physical activity and associated factors among adults in peri-urban and rural eastern Uganda: a population-based study. J Phys Act Health. 2016;13(11):1243-1254. doi:10.1123/ jpah.2016-0025

28. Gerovasili V, Agaku IT, Vardavas CI, Filippidis FT. Levels of physical activity among adults 18-64 years old in 28 European countries. Prev Med. 2015;81:87-91. doi:10.1016/j.ypmed.2015.08.005

29. Morseth B, Jacobsen BK, Emaus N, Wilsgaard T, Jørgensen L. Secular trends and correlates of physical activity: the Tromsø Study 1979-2008. BMC Public Health. 2016;16(1):1215. doi:10.1186/ s12889-016-3886-z

30. Dyck DV, Cardon G, Deforche B, De Bourdeaudhuij I. Urban-rural differences in physical activity in Belgian adults and the importance of psychosocial factors. J Urban Health. 2011;88(1):154-167. doi:10.1007/s11524-010-9536-3

31. Parks SE, Housemann RA, Brownson RC. Differential correlates of physical activity in urban and rural adults of various socioeconomic backgrounds in the United States. J Epidemiol Community Health. 2003;57(1):29-35. doi:10.1136/jech.57.1.29

32. Fan JX, Wen M, Kowaleski-Jones L. Rural-urban differences in objective and subjective measures of physical activity: findings from the National Health and Nutrition Examination Survey (NHANES) 2003-2006. Prev Chronic Dis. 2014;11:E141. doi:10.5888/pcd11.140189

33. Christie CD, Consoli A, Ronksley PE, Vena JE, Friedenreich CM, McCormack GR. Associations between the built environment and physical activity among adults with low socio-economic status in Canada: a systematic review. Canadian Journal of Public Health = Revue Canadienne De Sante Publique. 2020. doi:10.17269/s41997020-00364-9
34. Smith M, Hosking J, Woodward A, et al. Systematic literature review of built environment effects on physical activity and active transport an update and new findings on health equity. Int J Behav Nutr Phys Act. 2017;14(1):158. doi:10.1186/s12966-017-0613-9

35. Van Cauwenberg J, Nathan A, Barnett A, Barnett DW, Cerin E. Relationships between neighbourhood physical environmental attributes and older adults' leisure-time physical activity: a systematic review and meta-analysis. Sports Med. 2018;48(7):1635-1660. doi:10.1007/s40279-018-0917-1

36. Hamrik Z, Sigmundová D, Kalman M, Pavelka J, Sigmund E. Physical activity and sedentary behaviour in Czech adults: results from the GPAQ study. Eur j Sport Sci. 2014;14(2):193-198.

37. Poggio R, Serón P, Calandrelli M, et al. Prevalence, patterns, and correlates of physical activity among the adult population in Latin America: cross-sectional results from the CESCAS I study. Glob Heart. 2016;11(1):81-88.e81. doi:10.1016/j.gheart.2015.12.013

38. Oyeyemi AL, Oyeyemi AY, Jidda ZA, Babagana F. Prevalence of physical activity among adults in a metropolitan Nigerian city: a cross-sectional study. $J$ Epidemiol. 2013;23(3):169-177. doi:10.2188/jea.JE20120116

39. Gallus S, Lugo A, Murisic B, Bosetti C, Boffetta P, La Vecchia C. Overweight and obesity in 16 European countries. Eur J Nutr. 2015;54(5):679-689. doi:10.1007/s00394-014-0746-4

40. Wu YT, Luben R, Wareham N, Griffin S, Jones AP. Weather, day length and physical activity in older adults: cross-sectional results from the European Prospective Investigation into Cancer and Nutrition (EPIC) Norfolk Cohort. PLoS One. 2017;12(5):e0177767. doi:10.1371/journal.pone.0177767

41. Wolff D, Fitzhugh EC. The relationships between weather-related factors and daily outdoor physical activity counts on an urban greenway. Int J Environ Res Public Health. 2011;8(2):579-589. doi:10.3390/ijerph8020579

42. Chigbu CO Epidemiology of adult obesity in Enugu South East Nigeria. [Monographic Thesis]. Munich Germany: Center for International Studies Ludwig-Maxilians University Munich Germany; 2018.
Journal of Multidisciplinary Healthcare

\section{Publish your work in this journal}

The Journal of Multidisciplinary Healthcare is an international, peerreviewed open-access journal that aims to represent and publish research in healthcare areas delivered by practitioners of different disciplines. This includes studies and reviews conducted by multidisciplinary teams as well as research which evaluates the results or conduct of such teams or healthcare processes in general. The journal covers a very wide range of areas and welcomes submissions from practitioners at all levels, from all over the world. The manuscript management system is completely online and includes a very quick and fair peer-review system. Visit http://www.dovepress.com/testimonials. php to read real quotes from published authors. 